\title{
Simulation on microgrid connected PV system under balance and unbalance fault
}

\author{
Ameerul A. J. Jeman', Naeem M. S. Hannoon ${ }^{2}$, Nabil Hidayat ${ }^{3}$, Mohamed M. H. Adam ${ }^{4}$, \\ Ismail Musirin ${ }^{5}$, Vijayakumar $\mathbf{V}^{6}$ \\ ${ }^{1,2,3,4,5}$ Faculty of Electrical Engineering, Universiti Teknologi MARA (UITM), Malaysia \\ ${ }^{6}$ School of Computing Science and Engineering, VIT University Chennai, India
}

\section{Article Info}

Article history:

Received Oct 7, 2018

Revised Dec 6, 2018

Accepted Dec 19, 2018

Keywords:

Balanced fault

Microgrid

PV system

Simulink

Un-balanced fault

\begin{abstract}
This paper presents an analysis in Matlab/Simulink of a three-phase photovoltaic system under balance and unbalance faults in Matlab/Simulink. The aim of this paper is to investigate the performance of the system under various types of fault. The simulation involved various types of faults occurring at different distances from the point of common coupling of the PV system. This paper also aimed to identify what type of fault that may severely damage the system. The simulation results presented in this paper show that the three-phase fault in the microgrid was severely affecting the system since it involved all the three phases of the system while the distance of the fault occurrence is less influenced in the system. The purpose of this research is to observe the effect on the system based on the types of faults occur and the distance faults occur.
\end{abstract}

Copyright (C) 2019 Institute of Advanced Engineering and Science. All rights reserved.

Corresponding Author:

Naeem M. S. Hannoon,

Faculty of Electrical Engineering, Universiti Teknologi MARA (UiTM), 40450 Shah Alam, Selangor, Malaysia.

Email: hannoon.naeem@gmail.com

\section{INTRODUCTION}

Balanced faults affects the three phases equally. It is analysed to determine the voltage and current after the fault and used for the protection scheme design. Balanced faults can be divided as three phase open circuit fault, three phase short circuit fault and three phase short circuit to ground fault. Usually faults are associated with fault impedances. These impedances are assumed to be small and negligible. When there is short circuit, current is very high due to small impedances, hence assuming the fault impedances are zero in the analysis of faults. It is also used to design and specification of transducer, CT (current transformer), VT (voltage transformer), CB (circuit breaker) and relays in power system protection.

Unbalanced faults affect the three phase differently. The objective of analyzing unbalanced faults are the same as balanced faults which for protection scheme design. The most common types of unbalanced faults are single-line-to-ground fault, double-line fault and double-line-to-ground fault.

Faults are the unwanted contingencies that may occur in the three phase power system. These contingencies may affect the performance of the system. When all the faults occur during the simulation, it will surely affecting the performance of the three-phase PV systems. Thus leading to the questioning about the performance of the system during faults analysis. There are many types of fault that can be occur in the three phase power system. However, there will be one fault that may severely disturb the whole system once it occur. This situation needs to be analyse and determine a fault affecting the power system severely. Development of design and simulation in Matlab has always be one of the most technique to do some research based on power system. Furthermore, this method can easily be compare with any research done by other researchers. 
The objectives of this research are as follows;

a) To investigate the performance of the three-phase PV connected microgrid systems during balance and unbalance faults.

b) To analyze what type of fault that may severely disturb the system.

c) To perform simulation in Matlab/Simulink for a PV connected grid system.

The purpose of this paper is to simulate the PV connected grid system under several of balance and unbalance faults conditions. Balance faults in power system known as three-phase fault whereas fault occur at the three phases of the system. While unbalance faults consist of single-line-to-ground fault, line-to-line fault, and line-to-line-to-ground fault where these faults involves one or two phases with and without connected to ground. The behavior of the system need to be observe under this condition.

There are two types of faults which can occur on any transmission lines; balanced faults and unbalanced faults also known as symmetrical and asymmetrical faults respectively. Most of the faults that occur on power systems are not the balanced three-phase faults, but the unbalances faults. In addition, faults can be categorized as the shunt faults, series faults and simultaneous faults [1]. In the analysis of power system under fault conditions, it is necessary to make a distinction between the types of fault to ensure the best results possible in the analysis. However, for this project only shunt faults are to be analysed.

Series faults represent open conductor and take place when unbalanced series impedance conditions of the lines are present. Two examples of series fault are when the system holds one or two broken lines, or impedance inserted in one or two lines. In the real world a series faults takes place, for example, when circuit breakers controls the lines and do not open all three phases, in this case, one or two phases of the line may be open while the others is closed [1]. Series faults are characterized by increase of voltage and frequency and fall in current in the faulted phases.

The shunt faults are the most common type of fault taking place in the field. They involve power conductors or conductor-to-ground or short circuits between conductors. One of the most important characteristics of shunt faults is the increment the current suffers and fall in voltage and frequency. Shunt faults can be classified into four categories [4].

a) Single line-to-ground fault: this type of fault exists when one phase of any transmission lines establishes a connection with the ground either by ice, wind, falling tree or any other incident. $70 \%$ of all transmission lines faults are classified under this category [5].

b) Line-to-line fault: as a result of high winds, one phase could touch anther phase \& line-to-line fault takes place. $15 \%$ of all transmission lines faults are considered line-to-line faults [5].

c) Double line-to-ground: falling tree where two phases become in contact with the ground could lead to this type of fault. In addition, two phases will be involved instead of one at the line-to-ground faults scenarios. $10 \%$ of all transmission lines faults are under this type of faults [5].

d) Three phase fault: in this case, falling tower, failure of equipment or even a line breaking and touching the remaining phases can cause three phase faults. In reality, this type of fault not often exists which can be seen from its share of $5 \%$ of all transmission lines faults [5].

Any power framework can be dissected by computing the framework voltages and flows under ordinary and unusual situations [11]. It is fundamental to ensure the wellbeing of open [12]. The seriousness of the blame relies upon the short out area [13]. Blame examination must be directed in each area [14]. Deficiencies could occur because of regular occasions or mishaps [15].

\section{RESEARCH METHOD}

A PV connected microgrid system SimPowerSystems examples of Matlab/Simulink R2010a is used for the simulation. Figure 1 show the main model of the system. All the main data are collected from the PCC and centralized in Table 1. Figure 2 show the model of the PV farm.

From Figure 1, it is shown that all types of fault were placed at the proposed distance from PCC. The simulation of the system was run accordingly based on the type of fault followed by the distance of the fault occurrence. All the simulation data were recorded in the Table 1 mentioned. 


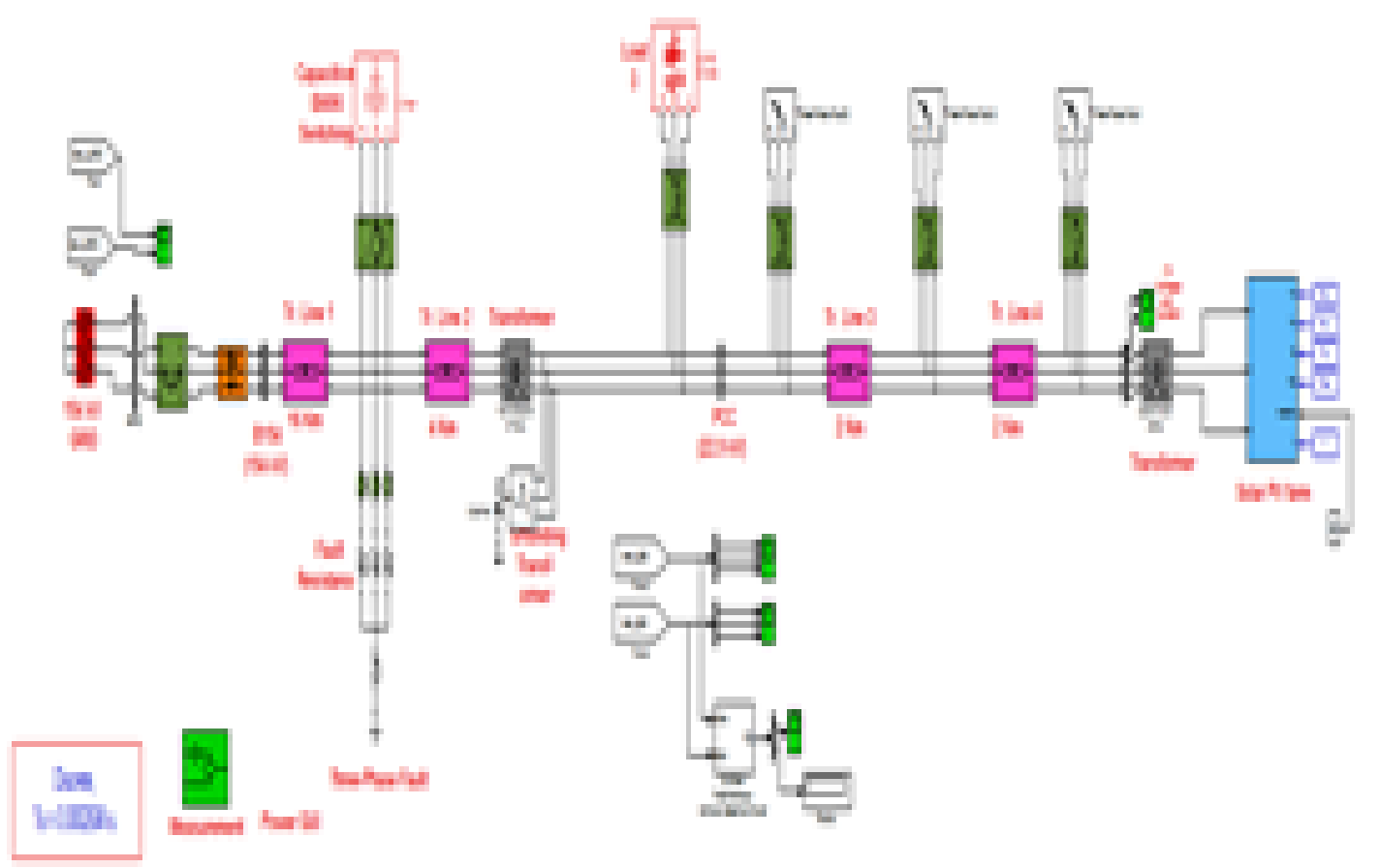

Figure 1. Simulink model of a PV connected microgrid system

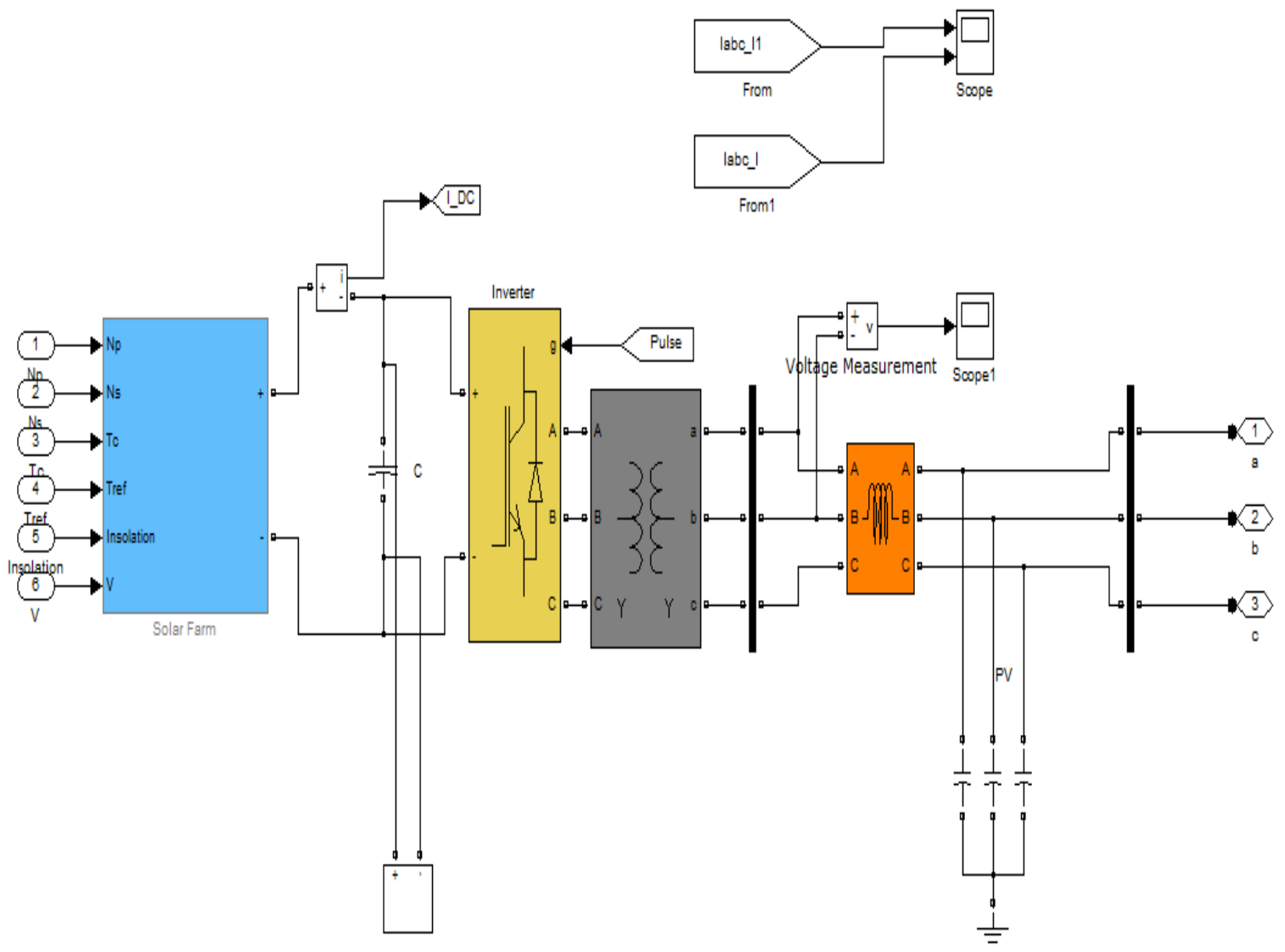

Figure 2. Simulink model of PV farm system 
For this paper, there were 4 types of fault identified to be used in the simulation which are single line to ground, line to line, line to line to ground and three phase fault. There were also 3 difference distances of fault occurrences needed to be study in this paper. Next, simulation circuit was designed based on the faults used and distances of the fault occurrence. Simulation of the circuit was run according to the type of fault and the distance of the fault from the PCC. All the data from the simulation were recorded and analysis was done according to the case study needed to be investigated.

\section{RESULTS AND ANALYSIS}

In this section, it is explained the results of research and at the same time is given the comprehensive discussion. From the results obtained, at normal operating conditions, voltage at all phases in the system remain stable which at 0.85 per unit. While current at 0.016 per unit. From all the faults occurred in the system, it can be observed that the nearer the fault to the PCC, the more unstable the voltage will become. While the current increases as the fault occurred nearer to the PCC. For single line-to-ground fault, only one phase affected by the fault while line-to-line and line-to-line-to-ground fault, two phases were affected by the fault. Three phase fault involved all three phases in the system. As observed, the most severe fault that causes the stability of the system to drop is three phase fault since the voltage drop below than other faults in the system because it involved all three phases in the system.

Table 1 depicted the voltages and currents, measured in PCC for various types of fault that occurred $2 \mathrm{~km}$ away from the PCC of the PV system. As observed from Figure 4 until 15, the evolution of the three phases of grid voltage during grid fault is expected for these types of short circuits. From the waveform obtained, it is shown that three phase fault has the most impact in the system compared to other faults. This is because three phase fault involved all three phases of the system. The same goes to current as shown in Figure 16 to 27 . When the fault occurred, the magnitude of the current increase rapidly, this situation will damage the equipment in the system. As observed, the most severe fault affecting the current was also three phase fault.

Table 1. Simulation Result of the PV System under Various Faults

\begin{tabular}{|c|c|c|c|c|c|c|c|}
\hline \multirow{3}{*}{$\begin{array}{l}\text { Type of short } \\
\text { circuit fault }\end{array}$} & \multirow{3}{*}{ Distance of PCC $(\mathrm{km})$} & \multicolumn{6}{|c|}{ PCC of the three-phase microgrid-connected PV system } \\
\hline & & \multicolumn{3}{|c|}{ Effective voltages (p.u.) } & \multicolumn{3}{|c|}{ Effective currents (p.u.) } \\
\hline & & $\mathrm{V}_{\mathrm{a}}$ & $\mathrm{Vb}$ & $\mathrm{Vc}$ & Ia & $\mathrm{Ib}$ & Ic \\
\hline \multicolumn{2}{|c|}{ Normal operating conditions } & 0.85 & 0.85 & 0.85 & 0.016 & 0.016 & 0.016 \\
\hline \multirow{4}{*}{$\begin{array}{l}\text { Single line-to- } \\
\text { ground }\end{array}$} & 4 & 0.38 & 0.75 & 0.9 & 0.73 & 0.0075 & 0.021 \\
\hline & 2 & 0.25 & 0.72 & 0.94 & 0.9 & 0.0075 & 0.022 \\
\hline & 0 & 0 & 0.68 & 1 & 1.17 & 0.007 & 0.022 \\
\hline & 4 & 0.45 & 0.52 & 0.85 & 0.85 & 0.44 & 0.0195 \\
\hline \multirow[t]{2}{*}{ Line-to-line } & 2 & 0.42 & 0.49 & 0.85 & 1.0 & 0.52 & 0.0194 \\
\hline & 0 & 0.42 & 0.42 & 0.85 & 1.2 & 0.65 & 0.0194 \\
\hline \multirow{4}{*}{$\begin{array}{l}\text { Line-to-line-to- } \\
\text { ground }\end{array}$} & 4 & 0.375 & 0.33 & 0.83 & 0.95 & 0.45 & 0.016 \\
\hline & 2 & 0.25 & 0.2 & 0.84 & 1.15 & 0.53 & 0.0155 \\
\hline & 0 & 0 & 0 & 0.86 & 1.45 & 0.62 & 0.015 \\
\hline & 4 & 0.37 & 0.335 & 0.392 & 0.92 & 0.51 & 0.61 \\
\hline \multirow{2}{*}{ Three phase } & 2 & 0.28 & 0.24 & 0.3 & 1.11 & 0.61 & 0.74 \\
\hline & 0 & 0 & 0 & 0 & 1.38 & 0.78 & 0.99 \\
\hline
\end{tabular}

\section{CONCLUSION}

This paper presents a study on three-phase microgrid-connected PV systems under balance and unbalance faults. Different types and different distances of the faults occurred will result in different types of impact on the PV system. The effect on PV system depends on the type of grid faults and distance that the fault occurred in the system. Balance fault contributed higher impact on the system compared to unbalance fault.

Future recommendation can be made in this paper where study on the performance of the PV side of the system in term of its output voltage, current as well as power. Observation on the frequency of the system can be made during occurrences of the faults. Fault protection can apply in this system in order to choose suitable protection relay for the system.

\section{ACKNOWLEDGEMENTS}

The author and researchers sincerely thank IRMI, 600-IRMI/DANA 5/3/LESTARI (0169/2016), and UiTM for providing lab facility and the fund to conduct this research smoothly. 


\section{REFERENCES}

[1] Turan Gonen, "Electric Power Transmission System Engineering, Analysis and Design”, Crc Press Taylor and Francis Group.

[2] Paul M. Anderson, “Analysis of Faulted Power Systems”, The Institute of Electrical and Electronics Engineers, Inc., 1995.

[3] Jun Zhu. "Analysis Of Transmission System Faults the Phase Domain”, Texas A\&M University. Master Thesis, 2004.

[4] C.L. Wadhwa, "Electrical Power Systems", pp 306, New Age International, 2006

[5] Hadi Saadat. Power System Analysis. Milwaukee Scholl of Engineering. WBC McGraw-Hill.

[6] A.Muhammad, "Simulation of Different Types of Faults on Northern Iraq Power System".

[7] I.J Nagrath, and D.P.Kothari, "Modern Power System Analysis", Tata McGraw-Hill Publishing Company Limited, New Delhi, India, 2012.

[8] V.K.Mehta and R.Mehta " "Principles of Power Systems", S.Chand and Company Limited, New Delhi, India, 2010.

[9] Miroslav D. Markovic, "Fault Analysis in Power Systems by Using the Fortescue Method", TESLA Institute, 2009.

[10] Norliana B. Salimun. "Phase Coordinates In Faulted Power System Analysis", Universiti Teknologi Malaysia. Master Thesis, 2010.X. S. Li, et al., "Analysis and Simplification of Three-Dimensional Space Vector PWM for Three-Phase Four-Leg Inverters," IEEE Transactions on Industrial Electronics, vol. 58, pp. 450-464, Feb 2011.

[11] Paul M. Anderson, "Analysis of Faulted Power Systems", the Institute of Electrical and Electronics Engineers, Inc., 1995.

[12] T.K Nagsarkar and M.S Sukhija, "Power System Analysis", New York Oxford University Press, pp.14$25,2005$.

[13] Hadi Saadat. Power System Analysis. Milwaukee Scholl of Engineering. WBC McGrawHill.

[14] Norliana B. Salimun. "Phase Coordinates in Faulted Power System Analysis", University Teknologi Malaysia. Master Thesis, 2010.

[15] Jun Zhu. "Analysis of Transmission System Faults the Phase Domain”, Texas A\&M University. Master Thesis, 2004 